\title{
COMPETITIVE ADVANTAGES OF THE BULGARIAN VITICULTURE AND WINE SECTOR AFTER THE ACCESSION TO THE EUROPEAN UNION
}

\author{
R. Beluhova-Uzunova*, A. Roycheva \\ Department of Economics, Agricultural University - Plovdiv, Bulgaria
}

\begin{abstract}
Viticulture is a traditional and important sector of Bulgarian agriculture and alongside with wine production has a strong export potential. Traditions, combined with favourable natural conditions promote the sector on international markets. The accession of Bulgaria to the European Union brought about a number of challenges and new requirements of the Common Agricultural Policy referring to product quality and competitiveness. The aim of the research is to analyse the competitive advantages of viticulture after the Accession and to highlight the opportunities for the sector in the programing period 2014-2020. Several of the commonly used indicators for the evaluation of competitive advantages have been applied such as the Relative index of export advantages - RXA, the Relative trade advantage - RTA and Related competitiveness - RC. The results of the study show the need for measures directed towards a balanced development of the viticultural sector in a few directions.
\end{abstract}

Key words: competitiveness, Common Agricultural Policy, innovations, export potential

\section{INTRODUCTION}

Viticulture in Bulgaria is a traditional agricultural subsector. Between the $60 \mathrm{~s}$ and 80 s of the 20th century, viticulture became a predominant agricultural sector with a total harvested area of more than 2 million decares. From the 1980s to the end of the last century, there was a serious decline in grape production. In this period significant areas were abandoned and there was very little investment in new vineyards.

Over the past 10 years following the accession of Bulgaria to the European Union (EU), a number of changes and transformations are observed. The membership to the EU provides a number of prerequisites for sustainable development of the sector but also sets serious challenges for holdings due to the need to compete directly with producers from other member states.

The aim of the study is to analyse the competitive advantages of viticulture after the accession and to highlight the opportunities for the sector in the programing period 2014-2020. The study is organized as follows: the first part reviews the theoretical background and

\footnotetext{
* Correspondence to: Economics, Agricultural University - Plovdiv, 12 Mendeleev Bld., 4000 Plovdiv, Bulgaria,email:rosicab_uzunova@abv.bg, Mobile phone: +359883326543
}

methodology of the survey. Second, the paper analyses the competitive advantages of viticulture based on the methodological framework. The final part presents the new opportunities for viticulture after the 2013 CAP reform and draws some conclusions and recommendations.

\section{THEORETICAL BACKGROUND AND METHODOLOGY}

International trade liberalization and globalization lead to an increase of competition and the analysis of competitiveness has become an important issue in the contemporary changing environment. Both competitiveness and competitive advantages represent a concept which can be described at a national, industry and firm level $(1,2)$. Competitive advantage is one of the important factors to retain long-term prosperity of a nation (3).

The term competitiveness has different definitions and interpretations. The Organisation for Economic Co-operation and Development (OECD) defines competitiveness as the "ability of companies, industries, regions, nations, and supranational regions to generate, while being and remaining exposed to international competition, relatively high factor income and factor employment levels on a sustainable basis" (4). The European Commission identifies competitiveness as "a sustained rise in the standards of living of a 
nation or region and as low a level of involuntary unemployment as possible" (5).

The trade negotiations over the past decades increased government interest in observing their country's competitiveness. Agriculture is a central and important sector in national economy and measuring its competitiveness is an object of serious discussions due to the recent trends in the global food and agribusiness sector, specifically the major growth of agricultural export.

Trade theory assumes that a nation's competitiveness is based on the concept of comparative advantage. The main principles are determined by Ricardo and the HeckscherOhlin model. The theories suggest that trade flows are the result of differences in production costs among countries and that a country will specialise in the production of a good in which it has a cost advantage (6). Such a concept is useful when national and international competitiveness are measured.

In scientific literature there are many indicators that could be applied for measuring competitive advantages of a particular country or region. Due to the specific characteristics of agriculture, the current methodology is based on Aleksiev (7).

Liesner (8) made the first empirical study in the area of relative competitive advantages (RXA).

Balassa (9) proposed an advanced measure of RXA. This is the widely used and modified measure of competitive advantages, which could be presented as follows:

$\mathrm{RXA}=\left(\mathrm{X}_{\mathrm{ij}} / \mathrm{Xit}\right) /(\mathrm{X} \mathrm{nj} / \mathrm{Xnt})$

where $X$ represents exports, $i$ is a country, $j$ is a commodity (or industry), $\mathrm{t}$ is a set of commodities (or industries), and $\mathrm{n}$ is a set of countries.

An RXA index greater than 1 demonstrates that the country has a comparative advantage in the commodity under consideration, since it has a strong export sector and shows higher competitiveness.

The main disadvantages of the coefficient are related to the fact that the indicator does not take into account the country's overall participation in the trade with a particular product or group of products, but only examines its exports. Second, the values of the indicator are spread over a wide range and do not give a realistic picture of the comparative export advantages.

The development of international trade at the end of XX century facilitated the overcoming of the limitations of the Balassa index related to the inability to report re-export in international trade. Another factor with an influence on the assessment of comparative advantages is the intervention of governments in the form of protectionism such as export subsidies, import restrictions, etc. They could not be evaluated by the Balassa index, which distorts the analysis of the competitiveness of a country.

Vollrath (10) modified the Balassa index and presented mainly three alternative ways of measurement of competitiveness. The indicator eliminates the role of re-export by including in the analysis of comparative advantages both the participation of the country in the export and the import of commodities. These indicators are called relative import advantages (RMA), the relative trade advantage (RTA), and the revealed competitiveness (RC). The last two indices are used in this study.

The relative import advantage (RMA) index is similar to the RXA, but relates to imports $(M)$ rather than exports:

$\mathrm{RMA}=\left(\mathrm{M}_{\mathrm{s}} / \mathrm{M}_{\mathrm{i}}\right) /\left(\mathrm{M}_{\mathrm{a}} / \mathrm{M}_{\mathrm{s}}\right)$

where $\mathrm{M}$ accounts for imports.

An RMA index of less than 1 indicates revealed comparative advantage and thus higher competitiveness.

The difference between the indices is called the relative trade advantage (RTA), a more observable indicator of revealed comparative advantage:

RTA=RXA-RMA

A positive value of RTA is an indication of a comparative advantage.

When RXA and RMA are compared in a logarithmic form, they are symmetric at the origin. Their difference is called the revealed competitiveness (RC). This is the indicator that most significantly eliminates the disadvantages of the Balassa index:

$\mathrm{RC}=\ln \mathrm{RXA}-\ln \mathrm{RMA}$ 


\section{COMPETITIVE ADVANTAGES OF BULGARIAN VITICULTURE AFTER THE ACCESSION TO THE EUROPEAN UNION}

Viticulture has been a traditional sector for Bulgaria since antiquity. It is important for the development of the country's economy, employed labour force, investments, the gross value added, export, but it is also related to the healthy lifestyle of the population. In the period between the $1960 \mathrm{~s}$ and the 1980s, viticulture became one of the structurally important sectors of Bulgarian agriculture. As a result, Bulgaria was among the top 10 wine producing countries in the world, as well as a leader in the production of table grapes.
BELUHOVA-UZUNOVA R., et. al. Following the 1989 socio-economic changes, the process of reduction of harvested areas began. The reasons were associated with the return of ownership in real terms and the refusal of a large number of owners to cultivate the land, low investment activity in the sector and structural changes in vineyard farms. On the other hand, some foreign markets were lost and taken by new serious wine producers, such as Chile, Argentina, Australia and others. In the years of transition and after the accession of Bulgaria to the EU, due to various factors, the share of viticulture in agriculture has decreased significantly.

Therefore, the results of the Balassa Index, presented on Figure 1, follow the trends of grape and wine production.

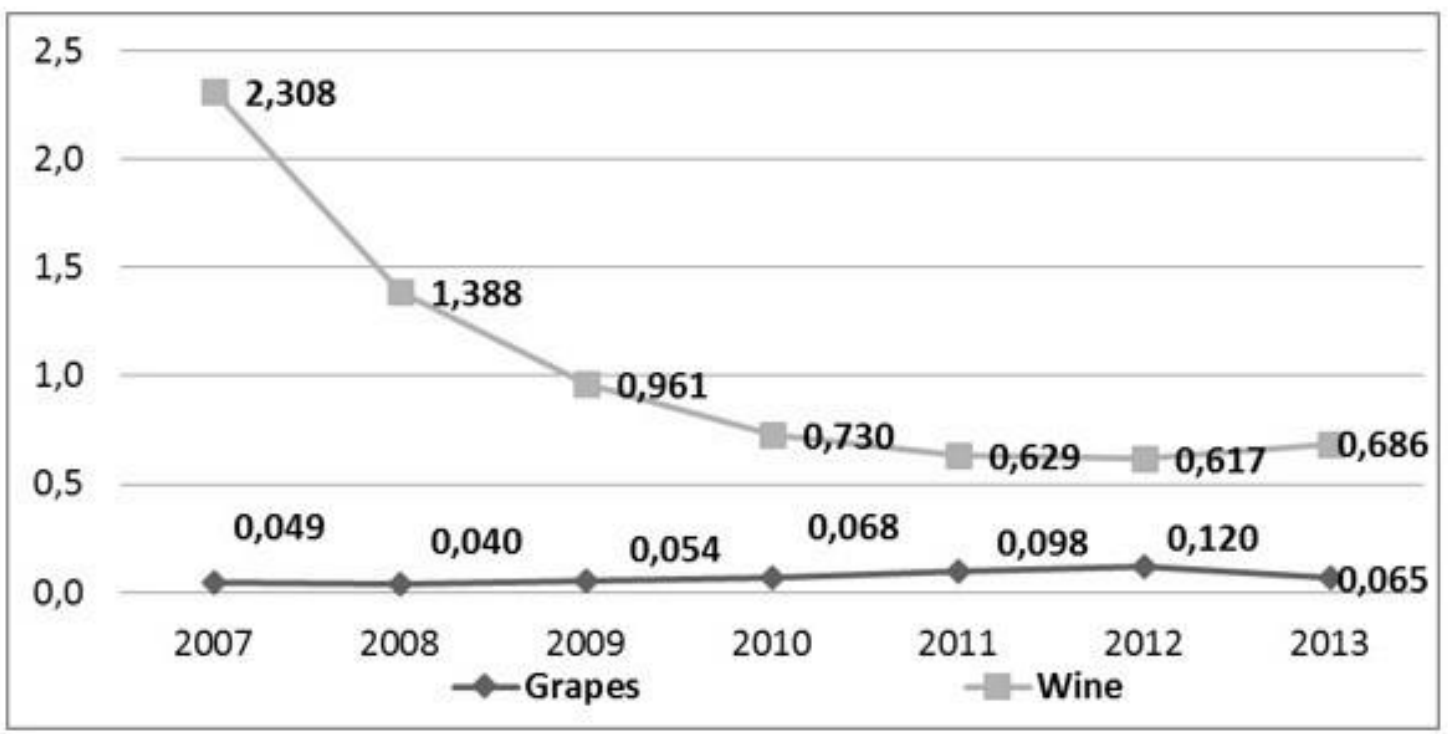

Figure 1. Balassa index of the Bulgarian viticulture and wine sector Source: Own calculations based on data from FAO

The value of the Balassa index for grape is less than 1 and is extremely low, which indicates that Bulgaria does not have competitive advantages in grape production. The indicator's value increases after 2010, but the results show a relatively alarming situation. This negative trend observed over the past 15 years, is confirmed by statistics. During the period 2010 - 2014, the harvested areas decreased by $24 \%$ to 628.9 thousand ha. At the same time unsupervised vineyards increased by more than 5000 ha only in 2014 compared to the previous year, reaching 103 thousand ha. The reduction of the area for the period 20032014 is more than two times (from 1310 thousand ha in 2003 to 629 thousand ha in 2014). The most drastic decline is observed in 2010 and 2013 (11). The decrease is significant and the result is the decline of structural importance of the sector in Bulgarian agriculture.
The reduction in harvested area and production is affecting the share of grape production in gross agricultural and crop production $(2,5 \%$ for 2012, 8,8\% for 2000). The same trend is observed in the share of wine grapes in the agricultural gross production, which has been continuously declining after 2007. The decrease observed in the share of the sector in crop production shows the divergent development of crop and grape production.

The negative trends in production and harvested areas caused a corresponding decrease in export and are the main reason for weakened competitive advantages of the country. The implementation of the CAP does not help to change the negative process and even raises the issue.

The dynamics of the Balassa index for wine production is different. During the first years after the accession the values of the indicator are above 1 and show that Bulgaria has 
BELUHOVA-UZUNOVA R., et. al.

competitive advantages in wine production. The access to the Common market since 2007 provides not only opportunities but also challenges. The export of wine decreased after 2009, reflected in a serious decline in the Balassa index. The negative trends diminished in the last two years but the Bulgarian wine sector still does not possess competitive advantages.

The dynamics in the indicators and the negative tendencies require more detailed analyses of the competitive advantages. Table 1 presents two main indicators introduced by Vollrath - Relative trade advantage and Revealed competitiveness.

Table 1. Competitive advantages of the Bulgarian viticulture and wine sector

\begin{tabular}{|c|c|c|c|c|}
\hline \multirow{2}{*}{ Years } & \multicolumn{2}{|c|}{ Relative trade advantage } & \multicolumn{2}{|c|}{ Revealed competitiveness } \\
\hline & Grapes & Wine & Grapes & Wine \\
\hline 2007 & $-0,2206$ & 1,7347 & $-3,8370$ & 1,3927 \\
\hline 2008 & $-0,2026$ & 1,1500 & $-1,7926$ & 1,7628 \\
\hline 2009 & $-0,0571$ & 0,7787 & $-0,7171$ & 1,6588 \\
\hline 2010 & $-0,0985$ & 0,5410 & $-0,8955$ & 1,3353 \\
\hline 2011 & $-0,1225$ & 0,4137 & $-0,8276$ & 1,1261 \\
\hline 2012 & $-0,2007$ & 0,3902 & $-0,9964$ & 1,0428 \\
\hline 2013 & $-0,1419$ & 0,2436 & $-1,2043$ & 0,7662 \\
\hline
\end{tabular}

Source: Own calculations based on data from FAO

The values of both coefficients for grape production are negative and confirm the results observed by means of the Balassa index. After the accession the trade balance indicates a downward trend in the export and an increase in the import of grapes.

One of the most important reasons for the decline in grape production is the large decrease in the newly created vineyards and unfortunately this trend has been increasing since 2008. A significant share (over 50\%) of the vineyards are over $20-25$ years old. The situation in the sector would get worse without a radical change and increasing the share of young vineyards. There is low investment activity and a deficiency of new technologies. The impact of the main instruments of the CAP on the sector is also one of the reasons for low competitiveness of grape production. The direct payments and market intervention proved to be ineffective for viticulture in Bulgaria. The financial support is extremely inadequate and could not substantially alleviate the economic situation of producers in a sector needing serious financial resources. According to the Agrostatistics Department, the average production costs in the grain and oilseed sectors are covered by direct payments of 24$26 \%$. At the same time, support for the grape production is significantly lower, about $4 \%$.

On the other hand, the changes in Relative trade advantage and Revealed competitiveness for wine production are much different. The indicators demonstrate competitive advantages in the period 2007-2013. However, a more indepth analysis of the data shows some negative trends. The Bulgarian export of wine significantly decreases from 87045 tones to 50007 tones - by over $40 \%$. The quantity of import also declines, but only by $2 \%$. Furthermore, while there is a decrease in the price of wine by about $2 \%$ in Bulgaria and on the world markets, the price of the wines imported in Bulgaria increases by approximately $8 \%$. The survey of the data helps to draw some conclusions.

There is a loss on traditional markets within the EU and third countries. In the wine sector, producers do not use modern and adequate marketing strategies for the realization of Bulgarian wine. The sector does not rely sufficiently on the unique and commercially significant local varieties, such as the red wine cultivars: Mavrud, Gamza, Broad Melnik vine, Pamid, and the white wine ones: Vratsa Misket, Tamianka, Dimiat, Misket Red, etc., which have been established and accepted well over the years on the Bulgarian and international markets.

The analysis of the indicators shows serious problems and issues in the competitiveness of Bulgarian viticulture. There are a lot of negative trends such as reduction of harvested area, production, export and gross value added. The low level of investments does not allow for a significant positive change and 
development of the sector in a right direction to take place. Another significant issue is the problem with the cooperation and producers' organizations of the farms. This prevents the producers from protecting their interests both in terms of the prices and realization conditions. On the other hand, the division of farmers creates tension between them, a decrease in prices and leads to a lasting trend of a downward development of the sector.

\section{OPPORTUNITIES FOR THE VITICULTURAL SECTOR IN BULGARIA 2014-2020}

The European agricultural policy for viticulture is ruled by a specific regime in the framework of CAP that evolved and transformed. By current rules, the sector is supported by the First pillar based on a financial envelope, called National Support Programs (NSPs) that allows member states to select one or more measures from a menu of possible instruments.

The nature of wine policy changed from the control of production in quantitative terms, towards more attention on the quality and improvement of competitiveness of European wine production in the global market (12). The wine policy is based on a system of simple and effective rules, capable of ensuring the market control. They also take into consideration the environmental role of viticulture in rural areas.

After the 2013 CAP reform, partially different options and measures are included in the programming of NSP (2014-2018). They could be organized in: promotion, restructuring and conversion of vineyards, green harvesting, mutual funds, harvest insurance, investments, innovation in the wine sector, product distillation. On the other hand, the supply control is ensured almost exclusively by the measure for production potential control, with actions organized by producers' organizations and inter-branch organizations.

The viticultural sector could accumulate financial support by the measures of the National Support Program 2014-2018 and the Rural Development Program 2014-2020. The National Support Program introduces three main measures: "Restructuring and Conversion of Wine Vineyards", "Promotion in Third Countries" and "Harvest Insurance". The implementation of the restructuring and conversion measure could lead to an increase of the number of viticultural producers, change the organizational structure of the sector, create new market-oriented farms and expand the production of quality wines. The "Promotions in Third Countries" and "Harvest
Insurance" measures do not have a direct effect on the investment in vineyards but they ensure a positive influence on grape production. The Rural Development Program (RDP) plays a crucial role for the modernization and technical innovation in viticulture. The rural development priorities are broken down into "focus areas". The main opportunities are related to modernization of agricultural holdings, support to semi-subsistence farms in the process of restructuring, producer organizations, agri-environment payment, etc. The use of structural funds could help the sector to overcome the existing problems and imbalances.

In order to change the negative trends in grape and wine production in Bulgaria, some recommendations could be formulated:

- Production of wines from local and unique commercially significant varieties;

- Focusing on the production of quality wines with Protected Geographical Name and Protected Designation of Origin, which are valuable for consumers worldwide and occupy a higher price niche;

- Consolidation of vineyards, innovative solutions in grape production, good practices for wine grapes;

- Implementation of technologies that lead to higher efficiency and productivity of vineyards and are environmentally friendly;

- Increasing the level of association and cooperation in the sector;

- Construction and restoration of irrigation facilities. One of the measures for the 20142020 period - restructuring and conversion - allows activities in this direction;

- Expansion of the application of the Global GAP and ISO standards;

- Bulgarian wines should be introduced on various fairs and events worldwide;

- Development of concrete marketing strategies aimed at expanding the share on traditional markets and entering new attractive commercial destinations.

\section{REFERENCES}

1. Anca, H., Literature Review of the Elution of Competitiveness Concept, Economic Science Series, Annals of the University of Oradea, 2012; 21(1):41-45.

2. Yercan, M., Isikli, E., International Competitiveness of Turkish Agriculture: A case for Horticultural Products, Paper prepared for presentation at the $98^{\text {th }}$ EAAE Seminar "Marketing Dynamics within the Global Trading System: New Perspectives", 2006: June/July. 
3. Porter, M., Competitive Advantage of Nations, New York: The Free Press, 1990.

4. Hatzichronoglou, T., Globalisation and Competitiveness: Relevant Indicators, OECD Science, Technology and Industry Working Papers, 1996/5, OECD Publishing, Organisation for Economic Cooperation and Development, Paris, France, 1996.

5. European Commission, European Competitiveness Report 2008, European Commission, Brussels, 2009.

6. Latruffe, L., Competitiveness, Productivity and Efficiency in the Agricultural and AgriFood Sectors, OECD, Food, Agriculture and Fisheries Papers, No. 30, OECD Publishing, Paris, 2011.

7. Aleksiev, A., Competitive Advantages of the Grain Sector. Monograph, Academic Publishing House of the Agricultural
BELUHOVA-UZUNOVA R., et. al. University, Plovdiv, 2012, ISBN 978-954517-147-5.

8. Liesner, H., The European Common Market and British Industry, Economic Journal, 68, 302-16, 1958.

9. Balassa, B., Trade Liberalisation and 'Revealed' Comparative Advantage, The Manchester School, 33, 99-123, 1965.

10.Vollrath, T., A Theoretical Evaluation of Alternative Trade Intensity Measures of Revealed Comparative Advantage, Weltwirtschaftliches Archiv, 130, 265-79, 1991.

11.Agrostatistics, Ministry of Agriculture, Food and Forestry, 2004-2014.

12.Pomarici, E., Sardone, R., La nuova OCM vino. La difficile transizione verso una strategia di comparto, Rapporto dell'Osservatorio sulle politiche agricole dell'UE, Inea, Roma, 2009. 